\title{
Lucien Goldmann
}

\section{ou a aposta comunitária}

MICHEL LÖWY

$\mathrm{E}$ NQUANTO NOS Estados Unidos e na América Latina o pensamento e a obra de Lucien Goldmann continuam suscitando um interesse muito grande, na França, ao que parece, $o$ autor foi encoberto por estranho esquecimento. É verdade que se trata de uma sociologia em ruptura total com a tradição dominante nas ciências sociais francesas, a qual vai de Auguste Comte a Lévi-Strauss e Louis Althusser, passando por Emile Durkheim. Mas, por outro lado, por sua reinterpretação de Pascal, ela não deixa de ser herdeira de uma corrente dissidente da cultura francesa moderna.

A importância de Goldmann resulta da dupla dimensão de sua obra, que é, a um só tempo, sociologia crítica e filosofia social. $\mathrm{O}$ tema da comunidade é o cimento que reúne esses dois momentos, proporcionando-lhes profunda coerência. Origina-se de uma crítica radical (porém dialética) da visão indipidualista do mundo, em todas suas formas e variantes, desde Descartes até o século XX.

O cogito cartesiano inaugura uma forma de pensamento que tão somente conhece o sujeito individual e faz do indivíduo isolado um começo absoluto: a mônada sem portas nem janelas de Leibniz, o empirismo inglês, o racionalismo do entendimento, o iluminismo, o homo economicus dos economistas clássicos, o Eu fichtiano, o novo cogito husserliano, o existencialismo são várias manifestações dessa mesma visão do mundo. Não se trata aí de lista exaustiva e poderiam lhe ser acrescentadas muitas outras formas não estudadas por Goldmann, como a economia marginalista, o darwinismo social, a corrente do individualismo metodológico nas ciências sociais etc.

Enquanto sociólogo da cultura, Goldmann se interessa pelos fundamentos sociais e históricos de tal individualismo e examina criticamente os laços existentes entre o desenvolvimento da economia de mercado, na qual o indivíduo aparece como fonte autônoma das próprias decisóes e atos, e o aparecimento das visões do mundo que vêem nesse mesmo indivíduo a fonte primeira do conhecimento e da ação. O iluminismo do século XVIII francês é o exemplo mais significativo. "No momento em que os homens perderam toda e qualquer consciência da existência de uma organização global supra-individual da produção e distri- 
buição de bens, os filósofos das Luzes exigem, em alto e bom som, o reconhecimento do entendimento individual como a instância suprema que não se deve submeter a qualquer autoridade superior" (1).

Sobre o fundamento do individualismo, há outros laços ainda que unem a filosofia das luzes à burguesia: suas principais categorias mentais correspondem todas, em certo grau, à estrutura da troca comercial que constitui o núcleo da nascente sociedade burguesa. Isso vale para o contrato, enquanto modo fundamental das relaçóes humanas, tanto como para a tolerância, a universalidade, a liberdade formal, a igualdade jurídica, a propriedade privada. Não se trata, para Goldmann, de negar a importância humana de várias dessas categorias, mas de mostrar seus limites e as conseqüências decorrentes de tal absolutização do indivíduo e do mercado, assim como a abolição de toda e qualquer realidade supra-individual - quer seja Deus, a totalidade, o ser ou a comunidade. O pensamento individualista concebe a sociedade apenas como uma soma de indivíduos e a vida social como simples produto do pensamento e das ações de grande número de indivíduos, cada um dos quais constitui um ponto de partida absoluto e isolado (2). A relação dos indivíduos com a totalidade social não pode ser diferente daquela que têm com o mercado: a observação de seu movimento objetivo, o estudo de suas leis cientificas.

Mas, como, partindo do indivíduo isolado, fundar uma ética, regras morais obrigatórias? Segundo Goldmann, não se pode, no contexto do individualismo burguês, demonstrar a necessidade de nenhum sistema particular de valores. $\mathrm{O}$ pressuposto fundamental da economia política clássica - mas também da filosofia política liberal - é que a procura egoística do próprio interesse por cada um dos indivíduos, conduz, por meio de uma harmonia implícita (a mão oculta), ao interesse geral de todos. Toda norma ética torna-se, portanto, supérflua, se não prejudicial. Na realidade, para o pensamento individualista conseqüente e levado aos últimos limites, a esfera moral, tanto quanto a religiosa inexistem enquanto campos específicos e relativamente autônomos. Os filósofos racionalistas (Descartes, Spinoza e seus discípulos) continuam, é claro, falando, com toda sinceridade, em moral e religião; mas, nas antigas formas éticas e cristãs, desenvolve-se um conteúdo radicalmente novo e, em última análise, amoral e irreligioso (3).

É verdade que o combate da filosofia das Luzes contra o obscurantismo da Igreja tinha um significado progressista e emancipador, que Goldmann nunca esquece, não deixando ao mesmo tempo de manifestar sua preocupação diante do vazio moral criado pela civilização individualista-burguesa e por aquilo que chama de indiferença axiológica do capitalismo: quando ameaçado, esse se adapta tão bem ao fascismo e à barbárie como as formas mais civilizadas do sistema democrático. Ele, ao mesmo tempo, chama a atenção para os perigos e as ameaças representados pela inexistência de normas válidas - resultado da própria lógica do 
individualismo radical - diante do desenvolvimento vertiginoso da técnica: "a ausência de forças éticas capazes de controlar a utilização das descobertas técnicas e de subordiná-las aos fins de uma verdadeira comunidade bem que poderia levar a consequiências que ninguém ousaria imaginar" (4). Goldmann deve pensar nos perigos do equilibrio do terror nuclear. Mas seu argumento aplica-se também às ameaças de catástrofe ecológica que pesam sobre a comunidade neste fim do século XX.

Nada mais errado do que deduzir de tal crítica uma rejeição unilateral da herança do iluminismo; trata-se apenas de mostrar as aporias que resultam dos pressupostos individualistas dessa filosofia e tentar superá-la - no sentido dialético da Aufbebung: negação, conservação, sobressunção) - por um pensamento comunitário novo. Marx considerava o socialismo moderno o herdeiro das mais altas conquistas do humanismo burguês. A visão de mundo do iluminismo, salienta Goldmann "encerra valores essenciais cuja salvaguarda deve urgentemente ser assegurada pelo socialismo": a tolerância, a liberdade e igualdade formais. A experiência trágica do estalinismo obriga os seguidores de Marx a se perguntarem, mais do que nunca, "como ... retomar esses valores dentro do socialismo e assegurar-lhe a sobrevivência numa base social e econômica diferente daquela em que nasceram?" (5).

Se a visão individualista do mundo origina-se do cogito cartesiano (eu penso, portanto, eu existo), o pensamento dialético começa, segundo Goldmann, "por uma frase, talvez excessiva, mas que é como se fosse um manifesto: o Eu é odioso" (Pascal). Goethe, Hegel, Marx e Lukács vão prolongar a intuição de Pascal ao fazer do sujeito transindividual o ponto de partida da ação e do conhecimento: para a dialética, "o fundamento ontológico da História é a relação do homem com os outros homens, o fato de que oEu individual só existe por detrás da comunidade". Em tal perspectiva, os demais seres humanos já não são simples objetos de conhecimento e observação, mas aqueles junto dos quais eu ajo (6).

Goldmann não questiona as descobertas de Freud: é verdade que a vida psíquica individual liga-se à libido e todo comportamento humano individual possui uma dimensão libidinal. Entretanto, as ações históricas, o domínio da natureza, a criação cultural não podem ser entendidos em sua significação, nem explicados em sua gênese senão partindo de um sujeito coletivo, ou antes, transindividual. Esse último não deve ser confundido com o misterioso sujeito coletivo proposto por Durkheim, ou seja, com uma consciência coletiva que se situaria fora ou ao lado da consciência individual: ele designa os grupos humanos, as coletividades nas quais os seres humanos pensam e agem juntos.

Tal concepção dialética do sujeito histórico apóe-se às visões individualistas do mundo tanto quanto àquelas que, ao modo do estruturalismo, eliminam o 
sujeito da teoria. Rejeitando essas duas posições correspondentes e complementares, representadas na filosofia francesa contemporânea por Sartre e Althusser, Goldmann vê no sujeito transindividual o único processo capaz de superar os dualismos do pensamento moderno: sujeito e objeto, juízos de fato e juízos de valor, explicação e compreensão, determinismo e liberdade, teoria e práxis (7).

Embora a História seja o produto da práxis de sujeitos humanos coletivos, todos os grupos não têm a mesma importância na vida social e cultural: "entre os inúmeros sujeitos transindividuais cuja ação se entrecruza e que constituem a vida de uma sociedade goblal, existe uma categoria cuja ação tem uma pertinência particular no tocante às transformações históricas e, principalmente, à criação cultural; trata-se dos grupos sociais em cujas práxis consciência e afetividade são orientadas não para um setor particular da organização social global (...) mas para a organização social como tal, para o conjunto das relações inter-humanas e das relações entre os homens e a natureza, quer tendam a conservá-las, quer tendam, ao contrário, a transformá-las de maneira radical: trata-se das classes sociais" (8). Goldmann pensa então, como Marx, que é preciso privilegiar o papel das classes sociais enquanto grupo cuja ação é orientada para a universalidade, para a estruturação da sociedade; que é preciso, também, ver nas relaçóes entre as classes a chave da compreensão da realidade social passada, presente e futura.

Significativa parte da obra de Goldmann, inspirada por essa premissa metodológica fundamental, tem por objeto a identificação das classes sociais que desempenham o papel de sujeito transindividual de certas criações culturais inclusive literárias e filosóficas. Le Dieu caché é o exemplo mais importante disso, por sua descoberta da nobreza de toga enquanto sujeito coletivo da vida trágica do mundo do século XVII - o jansenismo -, verdadeiro grito diante da expansão da moral individualista do racionalismo. A análise, em termos de sociologia da cultura, em nada diminui a importância de indivíduos como Pascal e Racine para dar a tal visão do mundo rigor e coerência. $O$ procedimento de Goldmann não pretende, de forma alguma, eliminar o papel dos indivíduos na ação histórica ou na criação cultural, mas inscrevê-los no contexto do sujeito transindividual e, particularmente, da classe social a que pertencem.

É verdade que Goldmann, no seu livro sobre a sociologia do romance, acreditou ter achado uma homologia estrutural direta entre as estruturas do mercado capitalista e as do romance como forma literária, sem passar pela mediação de uma consciência coletiva. No entanto, um sujeito transindividual (não necessariamente uma classe) é sugerido implicitamente por sua análise, à medida em que o romance expressa os sentimentos da inteligência criadora, ou seja, a dos criadores, escritores, artistas, filósofos, teólogos "cujos pensamentos e comportamento, mesmo sem escapar inteiramente ao poder degradante do mercado e da reificação, 
permanecem dominados por valores qualitativos"(9). Parece-me haver aí uma pista fundamental - não seguida por Goldmann - para entender vários fenômenos culturais modernos, a começar pelo romantismo (10).

Segundo Goldmann, não há como formular uma ética coerente - inseparável do conhecimento e da ação do grupo -, senão em relação a um sujeito transindividual. $O$ pensamento individualista conseqüente só conhece a verdade e o erro, o racional e o absurdo, o sucesso e o fracasso. A moral, enquanto campo próprio e relativamente autônomo, só pode existir "quando as açōes dos indivíduos são julgadas em relação a um conjunto de normas do bem e do mal que o transcendem" e se referem a um valor transindividual: um Deus sobre-humano ou a comunidade humana "sendo um e outra, a uma só vez, exteriores e interiores ao indivíduo" (11).

Desse ponto de vista, o pensamento dialético é herdeiro das inquietudes ligadas à visão trágica do mundo, e, particularmente, de Pascal: "O problema central do pensamento trágico, problema que só o pensamento dialético poderá resolver ao mesmo tempo no plano científico e moral, é o de saber se nesse espaço racional (...) existe ainda um meio, uma esperança qualquer de reintegrar os valores morais supra-individuais, se o homem poderá ainda reencontrar Deus ou aquilo que para nós é sinônimo e menos ideológico: a comunidade e o univer$s o$ ". Ao secularizar, dessa forma abrupta, a idéia trágica de Deus, Goldmann apaga com demasiada rapidez aquilo que faz a especificidade da religião em face do pensamento comunitário. Mas, na realidade, ele procura evidenciar a afinidade oculta entre o cristianismo trágico de Pascal e o socialismo marxiano.

Outra maneira de enfatizar tal parentesco é a redefinição, por Goldmann, do próprio conceito de religião, por meio do qual, "com condição de tomar essa última palavra no seu sentido mais amplo de $f^{\prime} e \mathrm{em}$ um conjunto de valores que transcendem o individuo, ele pretende abranger a ambos. A diferença essencial que separa um do outro é a ausência de perspectiva histórica da visão trágica, a qual admite o mundo existente como definitivo e imutável, sem esperança de porvir: trata-se de um pensamento incapaz de substituir o mundo atomista e mecanicista da razão individual por uma nova comunidade. A recusa absoluta e radical do mundo na visão trágica não conhece senão uma única dimensão temporal: $o$ presente" (12).

O pensamento dialético, o socialismo, ao contrário, orientam-se radicalmente para o porvir da comunidade humana. Mas enquadram-se também nessa religiāo em sentido lato: uma fé nos valores transindividuais. Em seu grande ensaio de 1960 sobre a filosofia das Luzes, Lucien Goldmann expressa nos seguintes termos as grandes opçóes que se apresentam à humanidade, em nossa época: "Eis a alternativa: sociedade dessacralizada, marcada pelo sucesso técnico, inteiramen- 
te racionalizada, ou então comunidade humana que, sem dúvida, há de retomar e desenvolver as possibilidades técnicas criadas pela sociedade burguesa, mas, ao mesmo tempo, deverá superar a alienação e criar uma nova religiosidade imanente - livre de qualquer transcendência - da comunidade humana e da História?" Uma leitura superficial desse trecho poderia sugerir uma oposição entre razão e esperança, mas alguns parágrafos adiante, a alternativa é explicitada na forma de escolha entre um saber técnico, indiferente aos valores da comunidade e uma fé imanente na comunidade, ou, em outros termos, "quem, do entendimento ou da razão, do capitalismo ou do socialismo será o futuro da humanidade" (13). Tratase, portanto, de uma superação do Verstand pela Vernunft dialética que, diante do desencantamento capitalista do mundo, abre-se para uma dimensão religiosa imanente, a uma só vez, sagrada e profana.

Melhor que o termo religiẩo (mesmo imanente), o qual poderia causar confusão, é a palavra fé que lhe parece mais apta a significar aquilo que ambas essas atitudes - apesar de tão diferentes uma da outra -, têm em comum. Segundo Goldmann, pode-se usar o conceito de fé - com condição de livrá-lo "das contingências individuais, históricas e sociais que o vinculam a tal ou qual religião precisa, ou até a religióes positivas em geral" - para designar certa atitude total, referente a valores transindividuais e capaz de abranger simultaneamente, numa unidade orgânica, "a compreensão da realidade social, o valor que a julga e a ação que a transforma” (14).

Afastando a suspeita de querer cristianizar o marxismo, Goldmann - por outro lado judeu e racionalista - insiste na oposição constante do marxismo com relação a toda e qualquer religião revelada que afirme a existência de uma transcendência sobrenatural ou supra-histórica: "A fé marxista é uma fé no porvir bistórico, feito pelos próprios homens ou, mais exatamente, que cabe a nós fazer por nossa atividade, é uma aposta sobre o sucesso de nossa açôes; a transcendência que é objeto dessa forma de fé já não é nem sobrenatural, nem trans-histórica, mas supra-individual, nada mais, mas também, nada menos". Enquanto pensamento racionalista, a dialética marxista é herdeira da filosofia das Luzes, mas por sua fé em valores transindividuais ela - depois de uma interrupção de seis séculos de racionalismo tomista e cartesiano - reencontra a tradição augustiniana de que se valiam Pascal e os jansenistas. $O$ ato de fé, afirma tranqüilamente Goldmann, é o fundamento comum da epistemologia agostiniana, pascaliana e marxista, embora se trate, nos três casos, de uma fé essencialmente diferente: evidência de transcendente, aposta sobre o transcendente, aposta sobre uma significaçáo imanente (15).

Se o termo fé aparece muitas vezes de forma retórica na literatura marxista, Goldmann é o primeiro a ter tentado explorar as implicações filosóficas, éticas, metodológicas e políticas de tal uso. Sem temer a beresis com respeito à tradição 
materialista-histórica, ele descobre, graças à sua interpretação pouco ortodoxa e profundamente inovadora de Pascal, a afinidade oculta, o túnel subterrâneo que religa, por sob a montanha das Luzes, a visão trágica (religiosa) do mundo e o socialismo moderno.

$\mathrm{O}$ ato de fé, que se acha no ponto de partida da opção marxista, como qualquér ato semelhante, baseia-se numa aposta: a possibilidade de realização histórica de uma comunidade humana autêntica (o socialismo). Ora, como mostram Pascal e Kant, não há nada, nos juízos no indicativo, nos juizos de fato científicos que permita afirmar o caráter errôneo ou válido da aposta inicial. Essa última não pode ser objeto de prova ou demonstração factual, mas é decidida por nossa ação comum, pela práxis coletiva. Por outro lado, apenas a realização futura do socialismo está sujeita à aposta: as outras teses ou afirmações do marxismo devem ser submętidas "à dúvida e ao controle permanente dos fatos e da realidade" (16).

As visões individualistas do mundo - racionalistas ou empiristas - ignoram a aposta. Essa não acha lugar senão no cerne das formas de pensamento inspiradas por uma fé $\mathrm{em}$ valores transindividuais: aquilo que a aposta pascaliana e a dialética têm em comum éo risco, o perigo de fracasso e a esperança do sucesso. O que as distingue é a natureza transcendental da primeira (aposta sobre a existência de Deus) e puramente imanente e histórica da segunda (aposta sobre o triunfo do socialismo na alternativa, oferecida à humanidade, da escolha entre o socialismo e a barbárie).

À pergunta: "É preciso apostar?", Pascal responde que todo ser humano já "está embarcado". Quaisquer que sejam as diferenças evidentes entre a fé de Pascal e a de Marx "a idéia de que o homem está embarcado, de que ele tem de apostar, constitui desde Pascal a idéia central de todo pensamento filosófico consciente de que o homem não é uma mônada isolada que se basta a si mesma, mas um elemento parcial, no interior de uma totalidade que o ultrapassa e à qual está ligado por suas aspiraçóes, sua ação e sua fé; a idéia central de todo pensamento que sabe que o indivíduo não tem condição de realizar sozinho, pelas próprias forças, nenhum valor autêntico e precisa sempre de um auxílio transindividual, na existência do qual ele deve apostar pois não poderia viver, nem agir, senão na perspectiva de um sucesso no qual tem de acreditar" (18). Mais do que uma homenagem a Pascal, essa passagem propõe uma nova interpretação, bastante heterodoxa, da significação do marxismo enquanto fé revolucionária.

Para um pensamento do progresso linear e da evolução histórica num único sentido, o paradoxo de um pensamento, a uma só vez, mais lúcido e retrógrado - Pascal diante de Descartes, representante do progresso científico e racional é incompreensível. Goldmann, por sua vez, não hesitava em reconhecer que o 
caráter trágico e não-revolucionário do jansenismo permitiu-lhe evitar certas ilusões do racionalismo progressista e entender, melhor que esse último, muitos aspectos da condição humana (como o mostrou Lukács, "um fenômeno análogo produziu-se na Alemanha, onde nasceu o pensamento dialético") (19). Tais observaçóes poderiam ter sido o ponto de partida de uma crítica marxista da ideologia do progresso, infelizmente nunca cogitada por Goldmann. Ele desconhecia a obra de Walter Benjamin e as publicações da Escola de Frankfürt pareciam-lhe demasiadamente pessimistas...

A afirmação audaciosa de uma afinidade eletiva entre a fé marxista e a fé trágica (cristã), e sua comum oposição às visões individualistas do mundo, não teve muita repercussão no pensamento cristão na França. Será preciso esperar até os anos 80, bem depois de sua morte, para que uma corrente cristã o mencione: a teologia da libertação latino-americana. Em seu livro La force historique des pauvres (1982), Gustavo Gutierrez, fundador da dita teologia, crítica e inovadora, de inspiração socialista, comunitária, escrevia o seguinte: "O individualismo é a marca mais importante da ideologia moderna e da sociedade burguesa. Para a mentalidade moderna, o homem é um começo absoluto, um centro autônomo de decisões. A iniciativa e o interesse individuais são o ponto de partida e o motor da atividade econômica. (...) Como o observa Lucien Goldmann, com perspicácia, o empirismo também é uma expressão do individualismo. Como o racionalismo, o empirismo é igualmente a afirmação de que a consciência individual é a origem absoluta do conhecimento e da ação". Em nota de pé de página, Gutierrez faz referência à edição latino-americana do ensaio de Goldmann sobre a filosofia das Luzes (La ilustración y la sociedad actual, Caracas, 1968) e acrescenta: "Muitas das observaçóes que fizemos sobre a relação entre a mentalidade iluminista e a economia capitalista inspiram-se nesse trabalho". Como o pensamento dialético de que Goldmann se valia, a reflexão cristã de Gutierrez refere-se a um sujeito transindividual: "O locus da teologia da libertação é outro. Está entre os pobres do subconsciente, nas massas indígenas, nas classes populares, está na presença desses grupos enquanto sujeito ativo e criador da própria história, nas expressões de sua fé e esperança no Cristo pobre, nas suas lutas para se libertar" (20).

Todavia, Gutierrez não se refere a Deus escondido: o desafio intelectual lançado por Goldmann, em sua análise paralela da aposta pascaliana e da aposta comunitária, fica ainda, em boa parte, por explorar...

\section{Notas}

1 Lucien Goldmann, La philosophie des Lumières, 1960. In: Structures mentales et création culturelle. Paris, Editions Anthropos, 1970, p. 29-30.

2 Idem, Ibidem, p. 27-37. 
3 L. Goldmann, Structures mentales et création culturelle, cit., p. 41, 89; Le Dieu caché, Paris, Gallimard, 1955, p. 39.

4 Idem, ibidem, p. 122 e 42 , respectivamente.

5 L. Goldmann, Les sciences humaines et la philosophie, Paris, Gonthier, 1966, p. 128.

6 Idem, ibidem, p. 24-25.

7 L. Goldmann, Pensée dialectique et sujet transindividuel. In: La Création culturelle dans la société moderne, Paris, Gonthier, 1971, p. 121-154.

8 Entretien avec L. Goldmann, VH 101, La Théorie, n. 2, E, 19, p. 43.

9 L. Goldmann, Pour une sociologie du roman, Paris, Gallimard, 1964, p. 30-31.

10 Remeto a meu livro (que se inspira amplamente no método de Lucien Goldmann) em colaboração com Robert Sayre, Répolte et mélancolie, le romantisme à contre-courant de la modernité, Paris, Payot, 1992.

11 L Goldmann, Le Dieu cache, cit., p. 40.

12 Idem, ibidem, p. 43-44.

13 L. Goldmann, Structures mentales et création culturelle, p. 111-112.

14 L. Goldmann, Le Dieu cache, cit., p. 99.

15 L. Goldmann, Le Dieu cache, cit., p. 99, 104.

16 Idem, ibidem, p. 99-100 e Réponse à MM. Picard et Daix, Structures mentales et création culturelle, p. 481.

17 L. Goldmann, Le Dieu cache, cit., p.334-336.

18 Idem, ibidem, p. 337.

19 L. Goldmann, Le Dieu caché et le marxisme, Structures mentales et création culturelle, cit., p. 484.

20 G. Gutierrez, La force historique des pauvres, Paris, Cerf, 1986, p. 173, 203. 


\section{Referências bibliográficas}

GOLDMANN, Lucien. Structures mentales et création culturelle, Paris, Editions Anthropos, 1970. . La philosophie des Lumières, 1960. In: Structures mentales et création culturelle, cit. - Réponse à MM. Picard et Daix, Structures mentales et création culturelle, cit. . Le Dieu caché et le marxisme, Structures mentales et création culturelle, cit. . Pour une sociologie du roman, Paris, Gallimard, 1964, p. 30-31. . Les sciences humaines et la philosophie, Paris, Gonthier, 1966.

. Pensée dialectique et sujet transindividuel. In: La Création culturelle dans la société moderne, Paris, Gonthier, 1971.

GUTIERREZ, G. La force historique des pauvres, Paris, Cerf, 1986.

LÖWY, Michael \& SAYRE, Robert. Répolte et melancolie, le romantisme à contre-courant de la modernité, Paris, Payot, 1992.

Michel Löwy é diretor de pesquisa em Sociologia do CNRS (Centre National de la Rescherce Scientifique, França). Foi professor-visitante do IEA-USP no segundo semestre de 1988.

Tradução de Jean Briant. O original em francês - Lucien Goldmann ou le pari communautaire - encontra-se à disposição do leitor no IEA-USP para eventual consulta. 